\title{
Research on Diversified Training of Teaching Skills for English Normal Students in the New Era
}

\author{
Zhuang Zhiqiang, Cai Lanlan* \\ School of Foreign Languages, Minnan Normal University, Zhangzhou, Fujian 363000 \\ School of Foreign Languages, Quanzhou Normal University, Quanzhou, Fujian, 362000 \\ cllan2004@163.com \\ *Corresponding author
}

Keywords: English normal students; teaching skills; diversification; training

\begin{abstract}
In the new period, strengthening the training of English Normal Students' teaching skills is an important way to improve students' professional quality in higher normal education. At present, however, the skill training in China's normal colleges and universities meets with such problems as the lack of targeted and diversified training, so this paper attempts to take this as a starting point, in view of the problems existent in English teaching skills of students in normal universities during the new period, to propose a new comprehensive training model. This paper first expounds the connotation of teaching skills and elements, and then combined with the characteristics of English subject, puts forward the pattern orientated by the study of theories and the practice of teaching skills as well as supplemented with diversified and characteristic teaching activities, thus training effective teaching skills for English normal students from the perspective of diversified cultivation to lay a good foundation for future English teachers' successful employment and teaching.
\end{abstract}

\section{Introduction}

As an important part of our country's teacher team, English normal college students are of great significance to the development of our country's education in the future. Teachers are considered as the foundation of the smooth running education, and to improve the overall level of education in our country, the promotion of the professional level of teachers is placed emphasis upon in "The National Long-term Education Reform and Development Plan (2010-2020)". And those English normal college students who are to teach in primary and secondary schools across the country will have a significant impact on a large number of primary and middle school students, so great importance should be attached to improving their teaching skills and professional ability by the relevant educators in colleges and universities and education departments. Taking the deficiency in the process of training normal students' teaching skills as the starting point, combined with the characteristics of effective English teaching, the paper explores the cultivation of diversified English teaching skills of students in normal universities in the new era.

\section{The Connotation and Elements of Teaching Skills}

\section{The Connotation of Teaching Skills}

Educational circles generally believe that a qualified teacher must possess lofty professional ethics, rich professional knowledge, and education and teaching ability. Our so-called "teaching skill" is the "ability of education and teaching" in the three aspects, i.e. teachers' behavior to promote students' learning by use of relevant knowledge and experience in the teaching process. The teaching skill lays stress on a series of behaviors that teachers, in order to accomplish their teaching objectives, employ 
theoretical knowledge of teaching related to pedagogy and psychology, professional knowledge, and effective teaching methods to promote students' effective learning in the teaching process. All along, great importance is attached to the training and assessment of basic skills for normal students such as "Three Handwritings and One Mandarin" and the expression ability of spoken English by normal colleges in China, but they are not all the teaching skills a qualified teacher should have.

\section{The Composition of Teaching Skills}

According to the content, teaching skills can be divided into teaching skills of classroom design, classroom organization, and the application of teaching methods.

First, classroom design teaching skill is that English normal students, based on the actual situation of teaching content, teaching objectives and their students' characteristics, optimize the orderly arrangement of various elements in the teaching process, and ultimately form a successful teaching plan. A successful teaching design is the decision-making of the whole teaching process, and is also a necessary condition for successful implementation of teaching and the completion of teaching objectives. Students' classroom design teaching skills are finally revealed by the way of teaching design, which will fully display the teaching contents and methods a teacher employs in a class, so it is a systematic arrangement and strategic decision of teaching contents, teaching methods, and all the teaching activities planned before class; it is the frame of a class. A successful teaching design is the basis of successful teaching practice, which requires English normal students' full understanding of teaching materials, the grasp of each teaching link, as well as the familiarity with teaching methods and blackboard design and other skills of lesson planning.

Second, classroom organization teaching skills mainly include organizing teaching activity skills, controlling classroom teaching skills, etc. The activity organization skill is mastering the review, introduction, new curriculum teaching, integrated skill training of listening, speaking, reading and writing and other teaching activities in the process of implementation of teaching; the ability to control the classroom is the application of appropriate classroom language and body language to the effective teaching organization and good teaching content presented in front of students. In case of emergency, the teacher should timely adjust the teaching plan, fully use his own teaching wisdom, correctly treat students' mistakes, and appropriately handle the embarrassment.

Third, the application of teaching method skills is of great importance in the new period. In addition to conventional teaching method skills such as the use of blackboard, teaching objects, and brief strokes, as well as modern teaching aids such as computer, projector, and video recorder, an English normal student should have the skills of designing blackboard, making courseware and drawing stick figures. Concerning the blackboard design, key and difficult points should be highlighted, and being one of the scenarios created in the process of English teaching, blackboard design is one of the necessary teaching skills of teachers. And teaching courseware is a teaching skill based on modern computer aided-media teaching, using power-point software, and making teaching courseware according to the teaching contents of the classes and the actual characteristics of students. A successful teaching courseware can vividly display the teaching content in front of students by means of computer multimedia, thus promoting students' English language learning by using their own various organs. When coming to the sketch teaching skill, a teacher based on the content of classroom teaching, in line with the target of English learning, quickly displays the realistic, lively, vivid and even exaggerated humorous creation of simple strokes, and therefore makes English main points reproduced. And the successful use of simple strokes in English teaching can enlarge the knowledge of spots to that of lines and sphere.

\section{An Analysis of the Training of Teaching Skills for English Normal Students}

At present, the problems in the training of normal students' teaching skills in China's normal universities are mainly manifested in the following two points:

First, the teaching skill training of English normal students lacks pertinence. The orientation of English teaching skills is very fuzzy in the majority of China's normal colleges, which still adopt the 
traditional training mode of the combination of pedagogy, psychology, subject instructional methods and teaching practice, but it is far beyond enough for English normal students to expertly master teaching skills. Therefore, it is difficult for English teachers cultivated in this way to meet the requirements of teachers' ability of education and teaching in the new period of basic education reform and development, and moreover, there will likely be no essential differences between English normal students and general graduates majoring in English.

Second, the training form of English normal students is relatively single in the process of cultivation. The teaching skills training in most of the normal colleges still gives priority to the teaching theories, along with two or four- month teaching practice in the senior year. The teaching mode of this kind may easily lead to normal students' seperation of theory from practice, making them unable to solve various problems with their own theoretical knowledge in practical teaching, and even unable to adapt in a short period to the English teaching in primary and secondary schools. So, in order to foster an English teacher troop with high quality, strong professional competence and proficient teaching skills according to the requirements of modern quality education and the new curriculum standard, the study of cultivating English normal students with comprehensive qualities has become an urgent issue in the new era for relevant educators to deal with.

\section{A Study of Diversified Training of Teaching Skills for English Normal Students in the New Era}

\section{Combine Long-term Professional Knowledge Learning with English Teaching Skills}

Generally speaking, college students are under great academic pressure such as pressure from TEM4, especially from TEM8, so they tend to focus on professional knowledge acquirement but neglect the training of teaching skills which is a necessary of a normal student. To implement the training of diversified teaching skills, the old teaching model, which isolates professional knowledge acquirement and teaching skill acquirement in teaching practice, should be changed, and teaching skill training should blend into professional knowledge acquiring process, thus realizing a win-win situation. English listening, reading, writing and translation skills training is the basic task of English education for primary and middle school students in the new period, and to train English normal students' ability in these aspects, a college or university tends to offer intensive and extensive reading and listening, speaking, writing, translation and other professional courses, each course taught by different teachers. Every professional course teacher, after teaching for years, having accumulated rich teaching experience, will have his own distinctive teaching features, and colleges and universities may make full use of this, utilizing every professional courses teachers' expertise to, in the process of cultivating students' professional knowledge, teach their long-accumulated characteristic teaching skills to their students and guide them in a particular skill. The teacher asks the students to review both the knowledge after each class and the teachers' special teaching methods, steps and characteristics, so that students can form the standard of normal students from the freshman year. In addition, according to the characteristics of professional courses, teachers can select appropriate teaching content, use the professional knowledge students have mastered in the classroom, and play a role for the students' knowledge. Teaching skills, as a practical knowledge, are experience knowledge depending on the situations, and teaching skills with stronger workability must be accumulated over time, so as to enhance their teaching skills imperceptibly. Teachers in the teaching process, through long-term guidance and training for students, help English normal students to better grasp the classroom teaching skills.

\section{The Combination of Teaching Theory and Practice in the Medium Term}

Long-term professional knowledge and training of teaching skills can help English normal students better master English listening, speaking, reading, writing, translation and other basic teaching skills. On the other hand, the medium-term cultivation refers to a comprehensive training in a shorter time, usually a few weeks, or one or two months, the purpose of which is not only to further consolidate the professional theoretical knowledge normal students have mastered, but also to bring 
the students into more direct contact with English classroom teaching in primary and middle schools, thus helping them realize the needs for primary and middle-school English learning in a more intuitive way. The cultivation of English normal students' teaching skills is strongly bound up with the guidance of professional knowledge. First, the teaching skills training of normal students is conducted through the establishment of professional courses related, such as teaching methods, the primary and secondary textbook research, a study of English learning strategies, and multimedia technology training of teachers, which can cultivate English normal students' systematic view of teaching, a clear understanding of the whole teaching framework, a better grasp of the characteristics of students in English learning, and a good knowledge of the theoretical support of English teaching skills. Second, direct contact with the English classroom teaching in primary and secondary schools helps improve the enthusiasm over the training of English teaching skills of normal students, making the future teaching skills learning and training more targeted. In the cooperation between higher institutions and local schools, normal students regularly sit in on classes and learn in primary and secondary English class to find their own shortcomings and improve teaching skills.

\section{Short-term English Teaching Skills Training Led by Second Classroom Activities}

The long and medium-term teaching skills cultivation and training help English normal students gain some theoretical understanding and experience of teaching skills, and meanwhile, they may constantly reflect on their own teaching in practice to find some deficiencies existent in their teaching skills, and students who self-reflect on the solution of problems improve their understanding of professional practice, thus ultimately achieving the effect of knowledge reconstruction and the improvement of teaching practice. Therefore, the short-term targeted teaching skills training can change the original subject-typed teaching method, highlight the problem-oriented learning method, and create an atmosphere of independent thinking. First, English subject itself has the characteristics of instrumentalism and humanism, with which normal students can carry out some activities of representative teaching case analyses such as the theme of "how to make English classroom more interactive and interesting". Second, the implementation of the short-term second classroom activities enables English normal students to develop the behavioral habits of teaching through research. The future teachers' teaching and research abilities and practical teaching skills will likely get common promotion through their participation in English teaching skills seminars, researches on forefront issues of teaching skills and other studies related to English teaching skills.

\section{Conclusion}

To sum up, this paper, focusing on the long-term, medium-term and short-term theoretical study and practice of normal students' teaching skills, with the carrier of diversified teaching activities, further strengthens, in external conditions fit for time and space, the breadth and depth of the skill training of English normal students, which is of some help for the future teachers to be qualified for the work as soon as possible.

\section{Acknowledgements}

Project: The Reform of Teaching Mode for Normal Students Under the Background of the Examination of Teachers' Qualification Certificate -- JAS141093 Class A of Educational Research Projects for Young and Middle-aged Teachers in Fujian.

\section{References}

[1] Wu Chenguang, Yang Lan. Problems in Teaching Design of Normal Students -- Based on Text Analysis of Teaching Plans [J]. Primary and Secondary School Audio-visual Education, 2016 (04).

[2] He Xueling. Strategies to Promote the Development of Pedagogical Skills for Normal Students [J]. Educational Exploration, 2015 (01). 
[3] Wang Hongyu. Problems and Countermeasures of Teaching Skills of Normal Students [J]. Educational Exploration, 2013 (12).

[4] Li Qingji. [J]. Education Theory and Practice Training Principles and Skills in Classroom Evaluation, 2012 (08).

[5] Wang Lanfang. Teaching Skills Training of Normal Students Majoring in Ideological and Political Education [J]. China Adult Education, 2012 (24).

[6] Li Yongfei, Zhao Qiaofang. Design of Skill Based Curriculum Teaching Model [J]. China Electric Power Education, 2012 (20).

[7] Wei Fang. A Book on English Teachers' Disccussion of English Class Teaching -- Comment on "Curriculum and People: Preservice English Teachers" Education. Chinese [J]. Journal of the Chinese Society of Education, 2015 (01).

[8] He Huaqing. Investigation on the Curriculum Design and Teaching of English Major Teachers in Local Normal Universities [J]. China Higher Education Research, 2015 (01). 